\title{
Anatomy of the mitral valve
}

\section{S Y Ho}

Heart 2002;88(Suppl IV):iv5-iv10

A ccording to Walmsley, ${ }^{1}$ it was Andreas Vesalius who suggested the picturesque term "mitral" to describe the left atrioventricular valve owing to its resemblance to a plan view of the bishop's mitre. Guarding the inlet to the left ventricle, the mitral valve prevents backflow to the left atrium during ventricular systole. In its open state, the valvar leaflets are like a funnel extending from the hinge line at the atrioventricular junction to the free margins. Tendinous cords attach the leaflets to two closely arranged groups of papillary muscles. The interchordal spaces serve as important pathways for blood flow. As emphasised by Perloff and Roberts, ${ }^{2}$ the mitral valve requires all its components, together with the adjacent atrial and ventricular musculature, in order to work properly. This review examines the component parts to provide the background for a better understanding of the mitral valve as seen in cross sectional anatomy and highlights pertinent features of its anomalies.

\section{GENERAL ANATOMY}

The valvar complex comprises the annulus, the leaflets, the tendinous cords, and the papillary muscles. Also important for its functioning is the left atrial musculature inserting to the leaflets and the myocardium to which the papillary muscles are inserted. The valve is obliquely located in the heart and has a close relation to the aortic valve (fig lA). Unlike the tricuspid valve which is separated by muscle from its counterpart, the pulmonary valve, the mitral valve is immediately adjacent to the aortic valve (fig $1 \mathrm{~B}$ ).

\section{The left atrial wall}

Although generally not appreciated as part of the mitral apparatus, Perloff and Roberts ${ }^{2}$ emphasised the important role of the atrial wall since left atrial enlargement can contribute to mitral regurgitation. The continuity of the atrial myocardium over the atrial surface of the mural ("posterior") leaflet makes this leaflet vulnerable to being displaced when the atrial chamber enlarges, ${ }^{3}$ but this hypothesis remains to be proven. Normally, extensions of atrial muscle mark the so-called ring when the valve is viewed from the atrium (fig lA). The degree of muscular extension varies from heart to heart and from area to area within the same heart. When the parietal atrioventricular junction is cut in profile, the variability of insertion of the hinge, or fulcrum, of the mural leaflet relative to atrial myocardium can be seen (fig 2A). At the aortic ("anterior") leaflet of the valve, the distal edge of atrial myocardium marks the hinge (fig 2B)

\section{Mitral annulus}

The annulus marking the hingeline of the valvar leaflets is more D shaped than the circular shape portrayed by prosthetic valves. The straight border accommodates the aortic valve allowing the latter to be wedged between the ventricular septum and the mitral valve. In this region, the aortic valve is in fibrous continuity with one of the two leaflets of the mitral valve. Expansions of fibrous tissues at either extreme of the area of continuity form the right and left fibrous trigones (fig 3). The atrioventricular conduction bundle passes through the right fibrous trigone.

Although the term annulus implies a solid ring-like fibrous cord to which the leaflets are attached, this is far from the case. In the area of aortic-mitral fibrous continuity, the distal margin of atrial myocardium over the leaflet defines the hingeline. When viewed from the ventricular aspect, however, the hingeline is indistinct since the fibrous continuity is an extensive sheet (fig 2B). McAlpine $e^{4}$ disfavoured the term annulus, preferring to describe the sheetlike fibrous area as the aortoventricular membrane that extended around the subvalvar region. Along the remainder of the annular circumference, the detailed studies of Angelini and colleagues ${ }^{5}$ demonstrated pronounced variations not only from heart to heart but within the same heart (fig 3). The same range of variations was found in hearts with floppy valves. Contrary to the report by Hutchins and colleagues, ${ }^{6}$ the so-called disjunction at the annulus was found as frequently in normal as in prolapsed valves. In agreement with previous studies, ${ }^{7}$ Angelini and colleagues $^{5}$ traced prongs of fibrous tissues from each of the fibrous trigones but these were not continuous around the orifice (fig 3). The annulus opposite the area of valvar fibrous continuity tends to be "weaker" in terms of lacking a well formed fibrous cord. This is the area affected in "annular dilation" and also most often involved in calcification of the

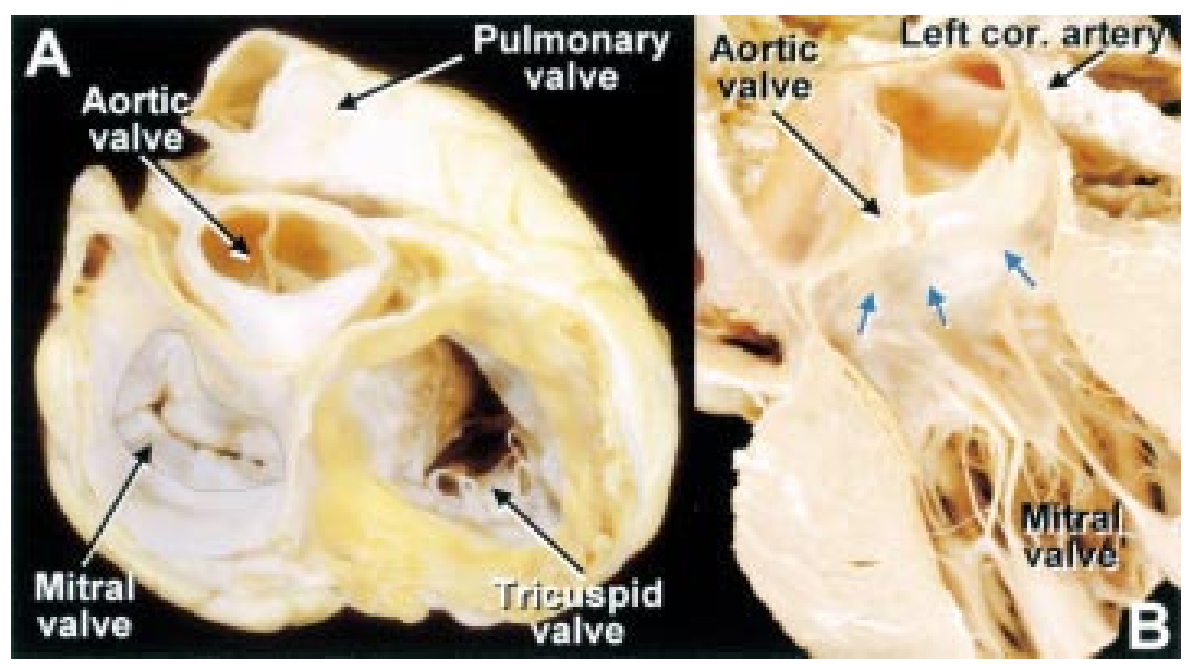

Figure 1 (A) View of the base of the heart in anatomical orientation shows the spatial relations of the four cardiac valves. The left heart valves are close together whereas the right heart valves are separated by myocardium. Dotted line marks the limit of atrial myocardium around the mitral orifice. (B) This dissection of the heart viewed from the anterior aspect shows the close relation between aortic and mitral valves in situ. Fibrous continuity between the valves (blue arrows) is related to the nonand left coronary sinuses of the aorta. 


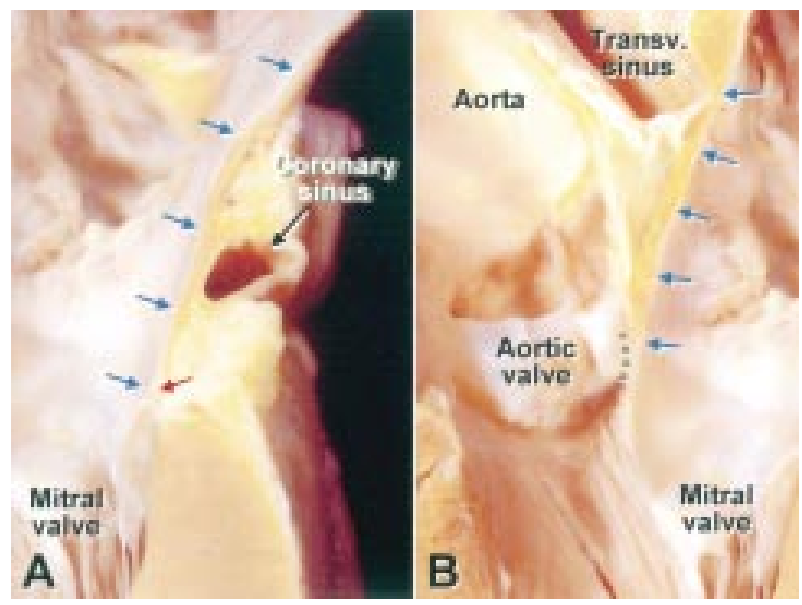

Figure 2 (A) The left parietal atrioventricular junction in profile shows the left atrial wall (blue arrows) running to the hinge (red arrow) of the mural leaflet of the mitral valve. (B) The aortic leaflet of the mitral valve cut in profile shows the atrial wall (blue arrows) reaching the leaflet. Grey dots mark the region of fibrous continuity between aortic and mitral valves.

annulus. With severe dilation, the minor axis of the valvar orifice becomes so distended that the leaflets, which are of fixed lengths, become unable to approximate each other.

\section{Leaflets}

Distinctly different from the tricuspid valve, the mitral valve has two leaflets although some may argue that it has four leaflets. ${ }^{8}$ These are notably different in shape and circumferential length. Owing to the oblique location of the valve, strictly speaking, its two leaflets do not occupy anterior/posterior positions nor is one of the leaflets "septal". The septal leaflet is characteristic of the tricuspid valve whereas neither of the mitral leaflets is attached to the septum. The corresponding terms for anterior and posterior are "aortic" and "mural". It is the aortic leaflet that is in fibrous continuity with the aortic valve (figs $1 \mathrm{~B}, 2 \mathrm{~B}$, and 3 ). The aortic leaflet has a rounded free edge and occupies a third of the annular circumference, whereas the other leaflet is long and narrow, lining the remainder of the circumference (fig 4A). The aortic leaflet hangs like a curtain between the left ventricular inflow and
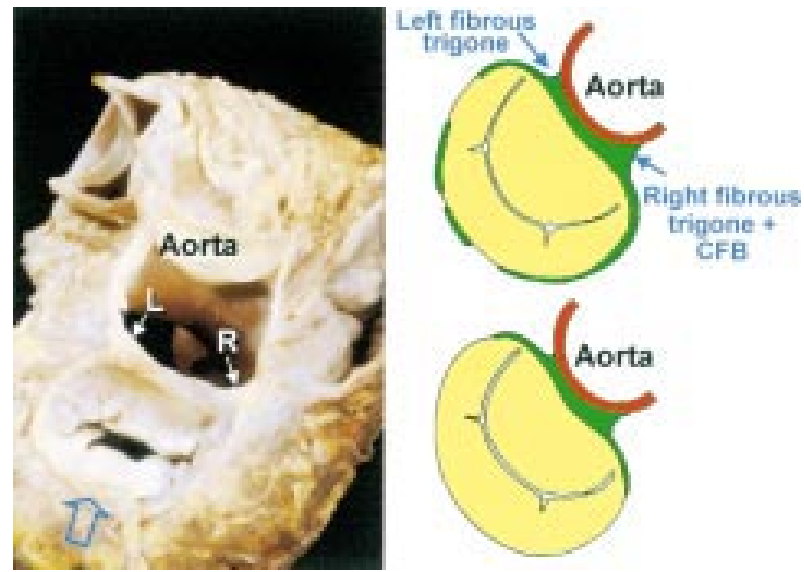

Figure 3 A dissection showing the left (L) and right (R) fibrous trigones revealed by removing the left and non-coronary aortic sinuses. The trigones are expansions of fibrous tissue at either end of the area of aortic-mitral valvar continuity. The right fibrous trigone together with the membranous septum forms the central fibrous body. The diagrams represent two of the cases reported in the work by Angelini and colleagues. ${ }^{5}$ They show the variation in completeness of the so-called valvar annulus (green areas).

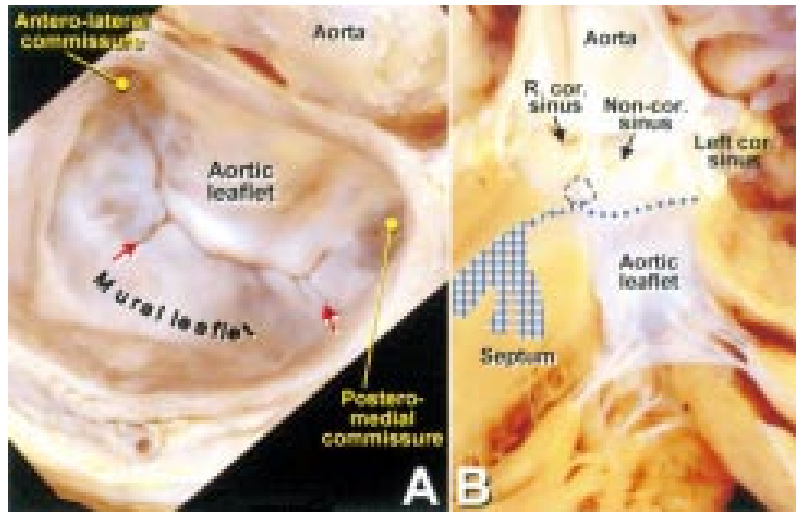

Figure 4 (A) The atrial aspect of the mitral valve shows the arrangement of the two leaflets between the commissures. The free edge of the mural leaflet has two clefts (red arrows) giving this leaflet the appearance of three scallops. Note the wider middle scallop.

(B) The aortic leaflet of the mitral valve hangs between inflow and outflow tracts of the left ventricle. Aortic-mitral fibrous continuity (dotted line) extends between the membranous septum (dotted circle) and the left fibrous trigone.

outflow tracts (fig 4B). When the valve is closed, this leaflet appears to form the greater part of the atrial floor but is approximately equal in area to the mural leaflet. ${ }^{9}$ It meets the mural leaflet to form an arc shaped closure line, or zone of apposition, that is obliquely situated relative to the orthogonal planes of the body. With the leaflets meeting, the view of the valve from the atrium resembles a smile. Each end of the closure line is referred to as a commissure (fig 4A). These are designated the anterolateral and posteromedial commissures. It is worth noting, however, that the indentations between leaflets do not reach the annulus but end about $5 \mathrm{~mm}$ short in the adult heart. Therefore, there are no clear cut divisions between the two leaflets. Furthermore, the free edge of the mural leaflet is often divided into three or more scallops or segments described as lateral, middle, and medial or assigned terms like P1, P2, and P3. ${ }^{10}$ Although three scallops are most common, the scallops are not equal in size. Rangnathan and colleagues $^{11}$ found the middle scallops to be larger in the majority of hearts ( fig 4A). Victor and Nayak ${ }^{12}$ likened the slits between scallops to the pleats of a skirt. When the mural leaflet is deformed in a floppy valve, the middle scallop is likely to be prolapsed.

Normally, the valvar leaflets are thin, pliable, translucent, and soft. Each leaflet has an atrial and a ventricular surface (fig 5A). When viewed in profile, two zones can be distinguished in the aortic leaflets and three zones in the mural leaflet according to the insertions of the tendinous cords (fig 5B,C). In both leaflets, there is a clear zone that is devoid of cordal attachments. Nearer the free edge, the atrial surface is irregular with nodular thickenings. This is also the thickest part, corresponding with the line of closure and the free margin. Tendinous cords attach to the underside of this area described as the leaflet's rough zone. The rough zone is broadest at the lowest portions of each leaflet but tapers toward the periphery, or commissure, of the closure line. The basal zone that is found only in the mural leaflet is the proximal area that has insertions of basal cords to its ventricular surface. Being distant from the ventricular wall, the aortic leaflet does not have attachments to basal cords. In normal valve closure, the two leaflets meet each other snugly with the rough zone and free edge in apposition but at an angle to the smooth zone (fig 6A).

When the closed valve is seen in profile, the major part of the closure line lies below the plane of the atrioventricular junction rising toward the commissures at the peripheral ends so that the atrial surface of the leaflets has a saddle-like 


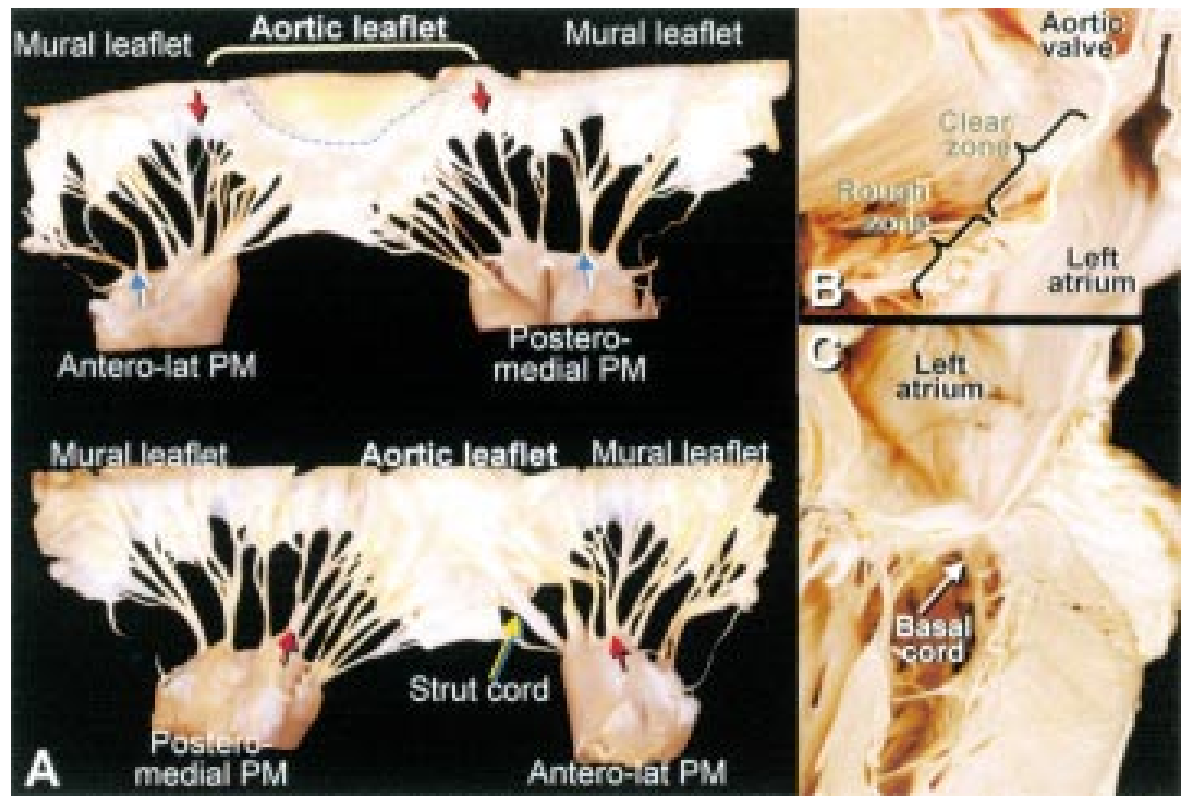

Figure 5 (A) Atrial surface (upper panel) and ventricular surface (lower panel) of a mitral valve spread open by cutting through the mural leaflet. The red arrows indicate the commissures supported by fan shaped commissural cords that are difficult to distinguish from cleft cords (blue arrows). Note the attachment of the cords to the edge and the rough zone of the leaflets. The broken line on the aortic leaflet marks the border between clear and rough zones. (B) This dissection profiling the aortic leaflet shows cordal attachments to the rough zone. (C) A basal cord inserts to the basal zone on the ventricular surface of the mural leaflet, close to its hinge. configuration..$^{13}$ Being tethered by the tensor apparatus, the line of coaptation in a normal valve does not extend above the level of the junction during ventricular systole (fig 6A).

Occasionally, the leaflets have a "hooded" appearance with slight pocket-like doming toward the atrium. The pockets occur between cordal attachments, but this appearance is not indicative of prolapse. ${ }^{14}$ By definition, prolapse of the mitral valve is the situation in which the leaflets extend above the plane of the atrioventricular junction during ventricular systole. ${ }^{15}{ }^{16}$ Prolapse can be produced by several mechanismsfor example, rupture of the tension apparatus or abnormal wall motion secondary to myocardial ischaemia. The best recognised morphology of primary prolapse is the floppy valve. ${ }^{16}{ }^{17}$ In these, the leaflets are redundant, thickened, and dome into the left atrial cavity. Two forms of prolapse are recognised. In some valves the leaflets protrude into the atrial cavity but the leaflets are still able to coapt ensuring valvar competence. In other cases, the free edge of the affected leaflet overshoots the closure line of the leaflet opposite with inevitable mitral regurgitation (fig 6B). Often, the leaflets of the floppy valve are not uniformly deformed. The mural leaflet is most frequently involved, either in isolation or with the aortic leaflet. Involvement of the aortic leaflet alone is rare. Deformation of the aortic leaflet affects the area close to the posteromedial commissure. In contrast, when involving the mural leaflet, the middle scallop is most often affected. This is thought to be a consequence of annular dilation in this region. ${ }^{18}$

The leaflets of floppy valves are thicker than normal, with thickness nearly twice normal in valves with moderate to severe regurgitation when measured on transthoracic echocardiography. ${ }^{19}$ Unlike the rigid valve distorted by rheumatism, the floppy valve is soft and even gelatinous in cases. Importantly, the commissures of floppy valves are not fused, further distinguishing these from valves affected by rheumatic endocarditis (fig 7).

\section{Tendinous cords}

The tendinous cords are string-like structures that attach the ventricular surface or the free edge of the leaflets to the papillary muscles. Characteristically, the tricuspid valve has cordal attachments to the ventricular septum allowing it to be distinguished from the mitral valve on cross sectional echocardiography. The tendinous cords of the mitral valve are attached to two groups of papillary muscles or directly to the postero-inferior ventricular wall to form the tensor apparatus of the valve. Cords that arise from the apices of the papillary muscles attach to both aortic and mural leaflets of the valve. Since cords usually branch distal to their muscular origins, there are five times as many cords attached to the leaflets as to the papillary muscles. ${ }^{9}$

There are numerous classifications of tendinous cords. One of the earlier classifications of cords is that cited in Quain's elements of anatomy, ${ }^{1}$ following the precedence of Tandler. ${ }^{20}$ This classification distinguishes three orders of tendinous cord

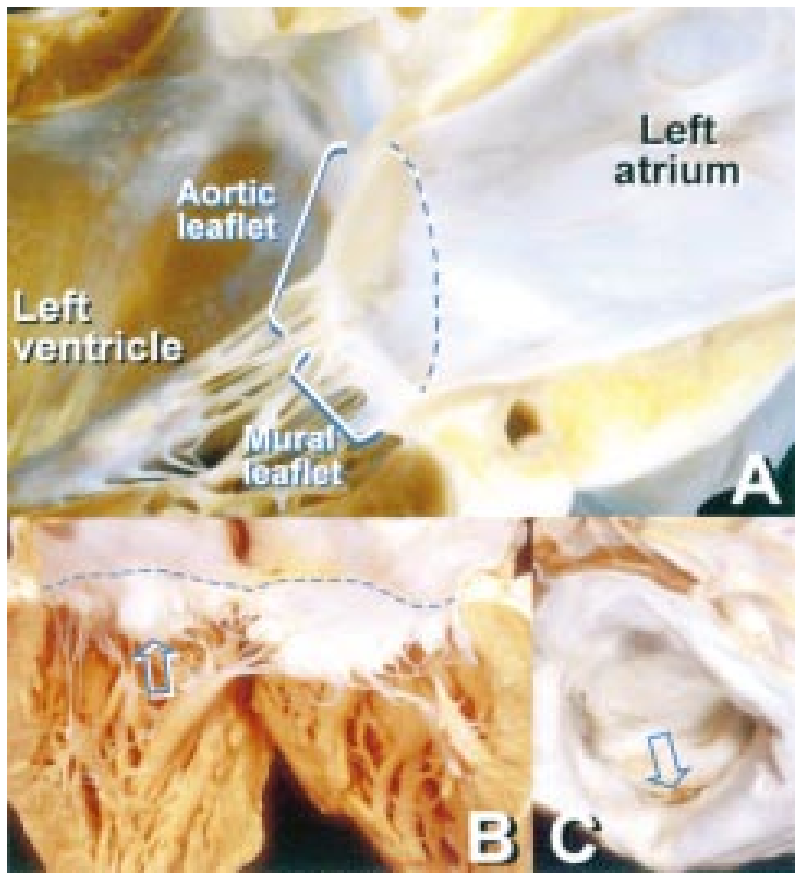

Figure 6 (A) The closure line of the mitral valve is seen in this simulated two chamber section through the long axis of the left ventricle. The closure line is below the level of the atrioventricular junction (broken line). (B) A case of prolapse of the middle scallop (arrow) in the mural leaflet overshooting above the level of the atrioventricular junction (broken line) when the valve closes. Note also the dome-like protrusions on the aortic leaflet. (C) Rupture of the tip of a papillary muscle affecting the aortic leaflet. 


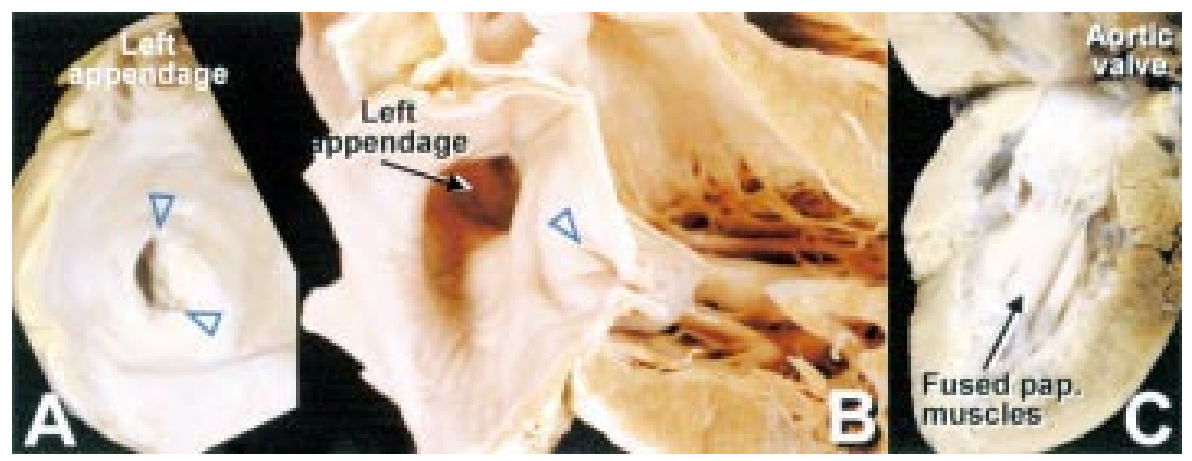

Figure 7 (A) Rheumatic mitral valve viewed from the atrium showing the stenotic crescent shaped orifice owing to fusion of the leaflets at the commissures ( $\nabla)$. (B) This longitudinal section through a rheumatic mitral valve shows fusion at the commissures $(\nabla)$ and thickening of the leaflets. (C) A single group of papillary muscles supports this parachute mitral valve. Note the short cords and loss of intercordal spaces exacerbating valvar stenosis.

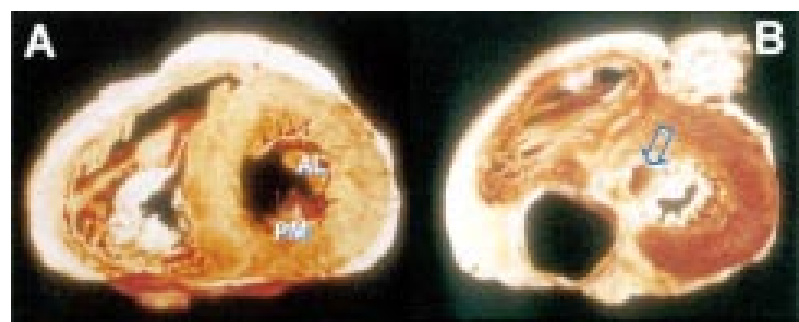

Figure 8 (A) Short axis section through the ventricles showing the oblique arrangement of the anterolateral $(\mathrm{AL})$ and posteromedial (PM) papillary muscles. (B) This section nearer to the base shows the aortic outlet (arrow) sandwiched between the mitral valve and the septum.

according to the site of attachment to the leaflets. The first order cords are those inserted on the free edge. They are numerous, delicate, and often form networks near the edge. Second order cords insert on the ventricular surface of the leaflets beyond the free edge, forming the rough zone. These are thicker than first order cords. Third order cords attach only to the mural leaflet since they arise directly from the ventricular wall or from small trabeculations. They insert to the basal portion of the leaflet and run only a short distance toward the free margin. In this area, webs may be seen in place of cords. Subsequent workers emphasised individual cords such as the commissural cords, ${ }^{21}$ strut cords, ${ }^{22}$ and cleft cords ${ }^{23}$ in relation to function. The Toronto group ${ }^{1123}$ distinguished between leaflet and interleaflet or commissural cords. Normally there are only two commissural cords, one supporting each free margin of the commissural region (fig 5A). These cords arise as a single stem but branch like the struts of a fan that, on closing and opening, allow the adjacent leaflets to coapt and to move apart.

Leaflet cords are of several forms. The most numerous are rough zone cords. Lam and colleagues describe these as single cords that typically split into three cords soon after their origin from the papillary muscle. One cord inserts to the free margin of the leaflet, and the other two to the rough zone, reinforcing the zone of apposition. These authors also described as atypical cords that have less than three branches. Rough zone cords in the mural leaflet are generally shorter and thinner than those found in the aortic leaflet. Among the rough zone cords of the aortic leaflet are two that are the largest and thickest. Termed strut cords, these arise from the tip of each papillary muscle and are thought to be the strongest. ${ }^{23}$ Basal cords are unique to the mural leaflet (fig 5D). In some hearts they are attached only to the middle segment.

Another type of cord, the cleft cord, is found only in the mural leaflet (fig 5A). Each is a miniature version of a commissural cord whose branches insert into the free margin between adjacent segments while the main stem runs into the rough zone. In the Toronto classification, ${ }^{11}{ }^{24}$ self evidently, the basal cords correspond to third order cords. ${ }^{1}$ The strut cords and parts of the rough zone and cleft cords correspond to second order cords. Parts of the rough zone cords, cleft cords, and the commissural cords that insert to the free edge of the leaflets correspond to first order cords. Muscularised cords averaging $3 \mathrm{~mm}$ in diameter are seen occasionally attached to the aortic leaflet. Their presence is thought to be benign. ${ }^{93}$

The work of Becker and de Wit ${ }^{14}$ showed that uniformity of cordal attachments was uncommon. Normal valves have a spectrum of cordal support and this lack of uniformity could lead to leaflet prolapse, particularly in older individuals. A subsequent study on a series of floppy valves revealed pronounced derangements in cordal branching and in their attachments to the leaflets, leaving parts of the affected leaflet less well supported. ${ }^{24}$

\section{Papillary muscles and left ventricular wall}

These are the muscular components of the mitral apparatus. As a functional unit, the papillary muscle includes a portion of the adjacent left ventricular wall. Tendinous cords arise from

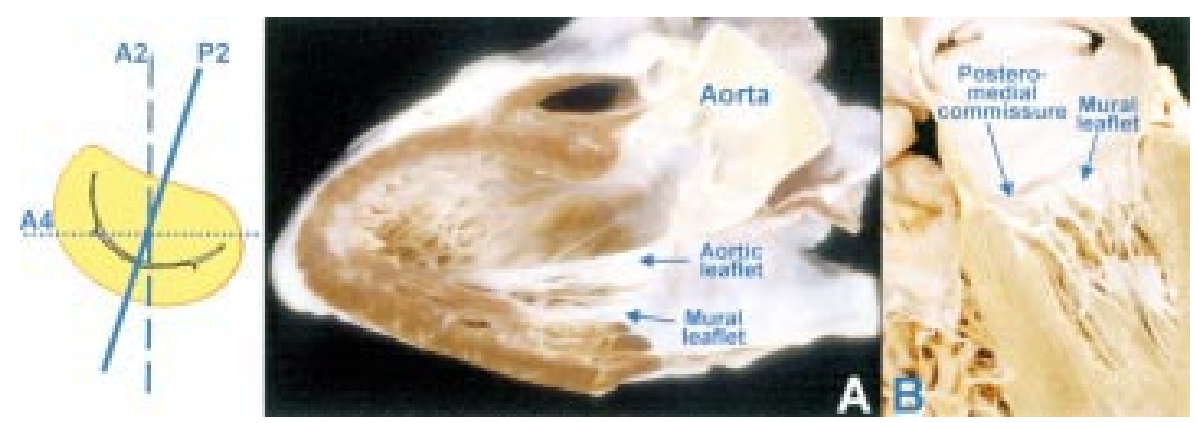

Figure 9 The diagram shows the planes of longitudinal sections through the mitral valve. The parasternal two chamber plane (P2) passes through the middle of both leaflets along the minor axis of the valve whereas the apical two chamber plane (A2) is at an angle to it. The apical four chamber plane (A4) is nearly parallel to the zone of apposition. (A) This simulated parasternal long axis section profiles the two leaflets nicely. (B) This simulated four chamber plane cuts the leaflets obliquely. It shows the aortic leaflet toward the posteromedial commissure and the mural leaflet toward the anterolateral commissure. 


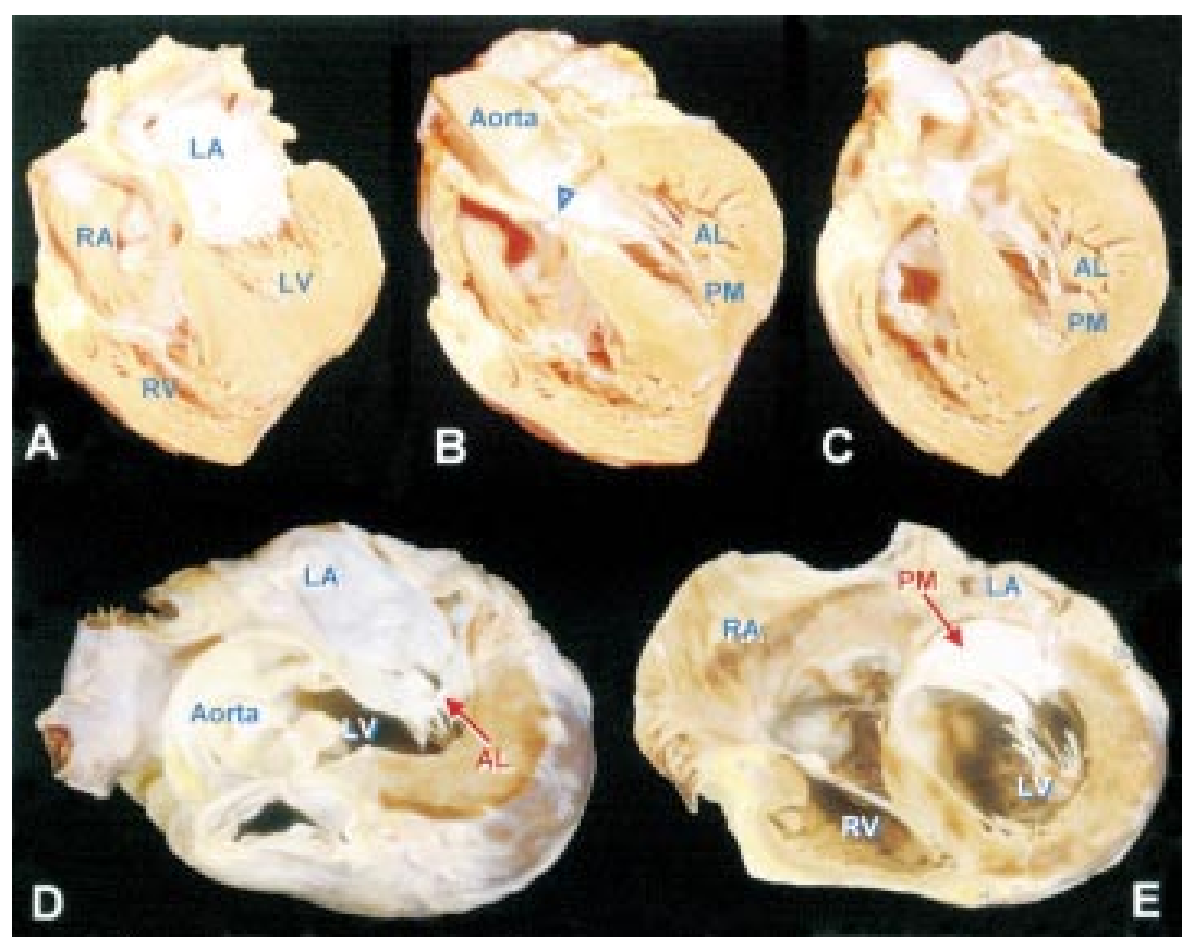

Figure 10 Sections A, B, and C are a series of heart sections replicating transgastric echocardiographic cuts of four chamber views foreshortened at the cardiac apex that allow visualisation of the tendinous cords and papillary muscles. Section A shows the off-set arrangement between tricuspid and mitral valves at the septum. Section B is a cut through the membranous septum $(\nabla)$ and shows the papillary muscles. Sections $D$ and $E$ replicate transgastric cuts through the closure line of the mitral leaflets that allow examination of the anterolateral (AL) and posteromedial (PM) commissures. LA, left atrium; LV, left ventricle; RA, right atrium; RV, right ventricle.

the tips of the papillary muscles. Alterations in the size and shape of the left ventricle can distort the locations of the papillary muscles, resulting in valvar function being disturbed. ${ }^{25}$ The papillary muscles normally arise from the apical and middle thirds of the left ventricular wall. ${ }^{22}$ Described in most textbooks as two in number, however, there are usually groups of papillary muscles arranged fairly close together. At their bases, the muscles sometimes fuse or have bridges of muscular or fibrous continuity before attaching to the ventricular wall. Extreme fusion results in parachute malformation with potential for valvar stenosis (fig 7C).

Viewed from the atrial aspect, the two groups are located beneath the commissures, occupying anterolateral and posteromedial positions. Rusted and colleagues' study ${ }^{26}$ of 200 normal hearts revealed a single anterolateral papillary muscle in $70 \%$ of cases. This contained a groove that pointed toward the commissure. The same study showed in $60 \%$ of cases that there are two or three papillary muscles, or one muscle with two or three heads, in the posteromedial location. Generally larger than the posteromedial muscle, the anterolateral muscle is supplied by an artery derived from the circumflex or anterior descending branch of the left coronary artery. Since most people have right dominance of the coronary pattern, it is the right coronary artery that most often supplies the posteromedial papillary muscle.

Rupture of a papillary muscle is usually the consequence of infarction of the adjoining ventricular wall. If rupture involves the entire papillary muscle or its group, there will be torrential regurgitation since approximately half the support of each leaflet will be lost. Rupture confined to one head of the papillary muscle complex will be similar to breaking a major cord (fig 6C). During systole, the affected free edge fails to meet with the other leaflet and moves into the left atrial cavity.

\section{SECTIONAL ANATOMY OF THE MITRAL VALVE}

Since the mitral valve is a complex with a unique arrangement of its component parts within the left ventricle, cross sectional imaging techniques including four dimensional echocardiography allow it to be visualised in its entirety by building up whole series of planes. The valve can be demonstrated in each of the orthogonal planes of the left ventricle, as well as in the orthogonal planes of the body.

Short axis planes through the ventricle display from apex to the cardiac base the oblique arrangement of the two groups of papillary muscles, the tendinous cords, the fish mouth appearance of the valvar opening, and the aortic outflow tract sandwiched between the ventricular septum and the mitral leaflet (fig 8). This view allows assessment of the area of the valvar orifice. At right angles to the short axis plane, the long axis plane such as that obtained from the parasternal window produces the so-called two chamber plane. In this view, the mode of closure of the leaflets and the level of the closure line relative to the atrioventricular junction is seen to best advantage (fig 9). The aortic and mural leaflets are readily distinguished, allowing detection of hooding, overshoot, or prolapse of each leaflet. The normal valve in closed position shows the aortic leaflet at an angle to the long axis of the ventricle but the mural leaflet is perpendicular. It should be noted that in some normal valves the leaflets may balloon slightly past the plane of the atrioventricular junction during systole, but the zone of coaptation remains below the plane. In valvar opening, the mural leaflet becomes nearly parallel to the inferior wall while the aortic leaflet parallels the ventricular septum.

The second series of long axis sections through the left ventricle, the so-called four and five chamber planes, allow distinction between tricuspid and mitral valves. Being more or less parallel to the zone of apposition between leaflets, it is poor for detecting problems of coaptation (fig 9B). The series of two chamber sections obtainable from the apical window cuts the leaflets obliquely, distorting the true leaflet length and motion. Views of the mitral valve through the transgastric and transoesophageal windows ${ }^{27-29}$ enable more detailed studies of the entire length of the zone of apposition, revealing the arrangement of cordal supports at all segments of the leaflets (fig 10).

\section{CONCLUSION}

The arrangement of the valvar apparatus, the close relation between the valves in the left heart and adjacent structures 
such as the central fibrous body and atrioventricular conduction bundle are all important in the clinical arena. Owing to the lie of the valvar apparatus at an angle to the orthogonal planes of the body, most cross sectional planes will reveal parts of the valve, but several views will be required to obtain the whole picture. Understanding the anatomy of the constituent parts of the mitral valve not only helps examination of these parts in cross sectional interrogation but also enhances appreciation of valvar anomalies.

\section{ACKNOWLEDGEMENT}

This work is funded by the Royal Brompton and Harefield Charitable Fund.

Correspondence to: Dr Siew Yen Ho, Paediatrics, Faculty of Medicine, National Heart \& Lung Institute, Imperial College, Dovehouse Street, London SW3 6LY, UK; yen.ho@ic.ac.uk

\section{REFERENCES}

1 Walmsley T. The heart. In: Sharpey-Schafer E, Symington J, Bryce TH, eds. Quain's elements of anatomy, 11 th ed, vol 4, pt 3. London: Longmans, Greens \& Co, 1929:42.

2 Perloff JK, Roberts WC. The mitral valve apparatus. Functional anatomy of mitral regurgitation. Circulation 1972;46:227-39.

3 Levy MJ, Edwards JE. Anatomy of mitral insufficiency. Progr Cardiovasc Dis 1962;5:119-44.

4 McAlpine WA. Heart and coronary arteries. An anatomical atlas for clinical diagnosis, radiological investigation and surgical treatment. New York: Springer-Verlag, 1975:39-56.

5 Angelini A, Ho SY, Anderson RH, et al. A histological study of the atrioventricular junction in hearts with normal and prolapsed leaflets of the mitral valve. Br Heart J 1988;59:712-6.

6 Hutchins GM, Moore GW, Skoog DK. The association of floppy mitral valve with disjunction of the mitral annulus fibrosus. N Engl J Med 1986;314:535-40

7 Zimmerman J. The functional and surgical anatomy of the heart. Ann R Coll Surg Engl 1966;39:348-66.

8 Yacoub M. Anatomy of the mitral valve, chordae and cusps. In: Kalmanson D ed. The mitral valve, London: Edward Arnold, 1976: 15-20

9 Roberts WC, Perloff JK. A clinicopathologic survey of the conditions causing the mitral valve to function abnormally. Ann Intern Med 1972;77:939-75.

10 Carpentier A, Deloch A, Dauptain J, et al. A new reconstructive operation for correction of mitral and tricuspid insufficiency. J Thorac Cardiovasc Surg 1971;61:1-13
11 Ranganathan N, Lam JHC, Wigle ED, et al. Morphology of the human mitral valve. II. The valve leaflets. Circulation 1970;41:459-67.

12 Victor S, Nayak VM. Definitions and functions of commissures, slits and scallops of the mitral valve: analysis of 100 hearts. Asia Pacific J Thorac Cardiovasc Surg 1994;3:10-16.

13 Cheng TO, Xie M-X, Wang X-F, et al. Evaluation of mitral valve prolapse by four-dimensional echocardiography. Am Heart J 1997;133:120-9.

14 Becker AE, de Wit APM. The mitral valve apparatus: a spectrum of normality relevant to mitral valve prolapse. Br Heart J 1980;42:680-9.

15 Gilbert BW, Schatz RA, Von Ramm OT, et al. Mitral valve prolapse: two-dimensional echocardiographic and angiographic correlation. Circulation 1976;54:716-23.

16 Becker AE, Davies $\mathrm{W}$. Pathomorphology of mitral valve prolapse. In: Boudoulas H, Wooley CF, eds. Mitral valve: floppy mitral valve, mitral valve prolapse, mitral valvular regurgitation. 2 nd ed. Armonk: Futura Publishing Company, 2000:91-114.

17 Davies MJ, Moore BP, Braimbridge MV. The floppy mitral valve. Study of incidence, pathology, and complications in surgical, necropsy, and forensic material. Br Heart J 1978;40:468-81

18 Bulkley BH, Roberts WC. Dilatation of the mitral annulus: a rare cause of mitral regurgitation. Am J Med 1975;59:457-63.

19 Malkowski MJ, Boudoulas H, Wooley CF, et al. Spectrum of structural abnormalities in floppy mitral valve echocardiographic evaluation. Am Heart J 1996;132:145-51.

20 Tandler J. Anatomie des Herzens: Handbuch des Anatomie des Menschen. Jena: Bandelben Gustav Fischer Verlagsbuchandlung, 1913 vol 3, Abt i, 84

21 Rusted IE, Schiefley $\mathrm{CH}$, Edwards JE. Studies of the mitral valve. I. Anatomic features of the normal mitral valve and associated structures. Circulation 1952;6:825-31.

22 Brock RC. The surgical and pathological anatomy of the mitral valve. $\mathrm{Br}$ Heart J 1952;14:489-513.

23 Lam JHC, Ranganathan N, Wigle ED, et al. Morphology of the human mitral valve. I. Chordae tendineae: a new classification. Circulation 1970:41:449-58.

24 Van der Bel-Kahn J, Becker AE. The surgical pathology of rheumatic and floppy mitral valves: distinctive morphologic features upon gross examination. Am J Surg Pathol 1986;10:282-92.

25 Burch GE, Giles TD. Angle of traction of the papillary muscles in normal and dilated hearts: a theoretical analysis of its importance in mitral valve dynamics. Am Heart J 1972;84:141-4.

26 Rusted IE, Scheifley CH, Edwards JE, et al. Guides to the commissures in operations upon the mitral valve. Proc Staff Meet Mayo Clin 1951:26:297-305.

27 Seward JB, Khandheria BK, Oh JK, et al. Transesophageal echocardiography: technique, anatomic correlations, implementation, and clinical applications. Mayo Clin Proc 1988;63:649-80.

28 Stümper O, Fraser AG, Ho SY, et al. Transoesophageal echocardiography in the longitudinal axis: correlation between anatomy and images and its clinical implications. Br Heart J 1990;64:282-8.

29 Louie EK, Langholz D, Mackin WJ, et al. Transesophageal echocardiographic assessment of the contribution of intrinsic tissue thickness to the appearance of a thick mitral valve in patients with mitral valve prolapse. J Am Coll Cardiol 1996;28:465-71. 